\title{
Xp11.2 translocation renal cell carcinomas in young adults
}

Linfeng $\mathrm{Xu}^{\dagger}$, Rong Yang ${ }^{\dagger}$, Weidong Gan ${ }^{*}$, Xiancheng Chen, Xuefeng Qiu, Kai Fu, Jin Huang, Guancheng Zhu and Hongqian Guo*

\begin{abstract}
Background: Little is known about the biological behavior of Xp11.2 translocation renal cell carcinomas (RCCs) as few clinical studies have been performed using a large sample size.

Methods: This study included 103 consecutive young adult patients (age $\leq 45$ years) with RCC who underwent partial or radical nephrectomy at our institution from 2008 to 2013. Five patients without complete clinical data were excluded. Of the 98 remaining patients, 16 and 82 patients were included in the Xp11.2 translocation and non-Xp11.2 translocation groups, respectively. Clinicopathologic data were collected, including age, gender, tumor size, laterality, symptoms at diagnosis, surgical procedure, pathologic stage, tumor grade, time of recurrence and death.

Results: Xp1 1.2 translocation RCCs were associated with higher tumor grade and pathologic stage $(P<0.05$, Fisher's exact test). During the median follow-up of 36 months (range: 3-71 months), the number of cancer-related deaths was 4 (4.9\%) and 3 (18.7\%) in the non-Xp11.2 translocation and Xp11.2 translocation groups, respectively. The Kaplan-Meier cancer specific survival curves revealed a significant difference between non-Xp11.2 translocation RCCs and Xp11.2 translocation RCCs in young adults ( $P=0.042)$.

Conclusions: Compared with non-Xp11.2 translocation RCCs, the Xp11.2 translocation RCCs seemingly showed a higher tumor grade and pathologic stage and have similar recurrence-free survival rates but poorer cancer-specific survival rates in young adults.
\end{abstract}

Keywords: Xp11.2 translocation, Renal cell carcinomas, TFE3, FISH

\section{Background}

Renal cell carcinoma (RCC) is the most common type of kidney cancer in adults and accounts for approximately $3 \%$ of adult malignancies and 90-95\% of neoplasms arising from the kidney [1]. The morbidity and mortality of RCC is still growing. RCC can be histologically classified into several subtypes, among which clear cell RCC is the most prevalent and represents $70-80 \%$ of kidney cancers [2].

Xp11.2 translocation RCC was first listed as a specific disease entity in the World Health Organization Classification of Tumors in 2004 [3]. This RCC subtype is defined by different translocations involving chromosome $\mathrm{Xp11.2,} \mathrm{all} \mathrm{of} \mathrm{which} \mathrm{result} \mathrm{in} \mathrm{transcription} \mathrm{factor} \mathrm{E3}$

\footnotetext{
* Correspondence: gwd@nju.edu.cn; doctorghq@gmail.com

${ }^{\dagger}$ Equal contributors

Department of Urology, The Affiliated Drum Tower Hospital of Medical

College of Nanjing University, Zhongshan Road 321, Nanjing, Jiangsu Province 210008, China
}

(TFE3) gene fusions. Several fusions of the TFE3 gene with different genes have been identified to date, including ASPL(17q25), PRCC(1q21), PSF(1q34), $\mathrm{NonO}(\mathrm{Xq} 12)$ and CLTC(17q23) [4]. Another subset of RCC is associated with transcription factor EB (TFEB) resulting from $\mathrm{t}(6 ; 11)(\mathrm{p} 21 ; \mathrm{q} 12)$. PRCC-TFE3 RCCs [5] and ASPL-TFE3 RCCs [6] are the most frequent kinds of Xp11.2 translocation RCCs.

Recent reports have shown that the incidence of Xp11.2 translocation RCC is low. Approximately onethird of pediatric RCCs are estimated to be Xp11.2 translocation RCCs associated with TFE3 gene fusion [7]. Several studies have recently evaluated its incidence as $0.9 \%(6 / 632)$ in adult RCCs [8], $15 \%(4 / 26)$ in young adult RCCs [9], and 54\% (7/13) in child RCCs [10].

A meta-analysis by Rao et al. [11] demonstrated that TFE3 + pediatric RCCs were associated with a poorer outcome and higher stage (III/IV) than TFE3-RCCs. 
Komai et al. [12] reported that young patients ( $\leq 45$ years) with RCC had similar recurrence-free survival rates but better cause-specific survival rates compared with older patients. In that study, Xp11.2 translocation RCCs accounted for at least one half of the young patients with RCC who had developed recurrence.

Until now, few clinical studies have examined the biological behavior of Xp11.2 translocation RCCs in young adults ( $\leq 45$ years). In this study, we aimed to better define the biological behavior of Xp11.2 translocation RCCs and to determine whether its clinical outcomes differ from those of non-Xp11.2 translocation RCCs in young adults.

We hypothesized that Xp11.2 translocation RCCs have poorer prognosis than non-Xp11.2 translocation RCCs in young adults. The objectives of this study were as follows: (1) to compare the clinicopathologic data of Xp11.2 translocation RCCs with that of non-Xp11.2 translocation RCCs and obtain the clinicopathologic features that correlated with Xp11.2 translocation RCCs, and (2) confirm if cancer-specific survival (CSS) and recurrence-specific survival (RFS) of Xp11.2 translocation RCCs were significantly different from those of non-Xp11.2 translocation RCCs.

\section{Methods}

\section{Study population}

Of the 879 consecutive adult RCCs in our institution from 2008 to 2013, 103 patients were in the age range of 18-45 years. Five cases without complete clinical data were excluded. Of the remaining 98 patients, there were 16 with Xp11.2 translocation RCCs, 61 with clear cell RCCs, 10 with papillary RCCs, 9 with chromophobe RCCs and 2 with unclassified RCCs. In this study, we defined young age as $\leq 45$ years according to definitions used in previous studies $[9,12]$. We diagnosed Xp11.2 translocation RCCs with positive fluorescence in situ hybridization (FISH) after initial screening according to medical history, age, pathologic morphology and subsequent TFE3 immunostaining. The study was approved by the Committee on Medical Ethics of Nanjing Drum Tower Hospital, Jiangsu, China. All patients provided written informed consent.

\section{Immunostaining}

To investigate the incidence of $\mathrm{Xp} 11.2$ translocation RCC, TFE3 immunostaining was performed on paraffinembedded tissue with the primary antibody TFE3 (Millipore, Billerica MA, US) using the manual overnight incubation methodology (using heat-induced epitope retrieval and the Dako Envision detection system).

\section{FISH}

A dual-color break-apart FISH assay for TFE3 gene rearrangement at the Xp11.2 region was performed on the
TFE3 positively stained tissue using a self-designed polyclonal break-apart probe. In brief, FISH of interphase nuclei was performed on 4- $\mu \mathrm{m}$-thick paraffin-embedded sections. The telomere sides of TFE3 gene cloning fragments (CTD-2516D6, CTD-2522 M13, and RP11-416B14) were labeled with fluorescein-12-dUTP and the centromeric sides of TFE3 gene cloning fragments (CTD-2312C1, CTD-2248C21, and RP11-959H17) were labeled with tetramethylrhodamine-5-dUTP. After sample preparation, hybridization with labeled DNA was performed overnight. Slides were counterstained with 4, 6-diamidino2-phenylindole (DAPI, Vysis, Abbott Park, IL, USA) and analyzed using an Olympus BX-51 fluorescence microscope (Center Valley, PA, USA). Co-localization of red and green signals in tumor nuclei was considered negative, and a split signal in more than $10 \%$ tumor nuclei was regarded positive for TFE3 rearrangement.

\section{Assessment}

The collected clinicopathologic data were as follows: age, gender, tumor size, laterality, symptoms at diagnosis, surgical procedure, pathologic stage, and tumor grade. All patients presented with tumor-free status after nephrectomy because no surgery was conservative or cytoreductive.

All patients had undergone a thorough medical history interview, physical examination, radiographic staging according to the computed tomography and/or magnetic resonance imaging of the abdomen as well as chest radiography. If warranted by the patient symptoms or physical examination findings, bone scans and brain imaging were performed.

The characteristics of the 98 patients are summarized in Table 1. The patients were followed up every 3-12 months with imaging studies. At each consultation, the patient's status (alive or dead) and the degree of tumor progression were determined. In the present study, the endpoints of follow-up were CSS and RFS.

\section{Statistical analysis}

The intergroup differences in the categorical and continuous variables were analyzed using Fisher's exact test and Student's $t$ test, respectively. The CSS and RFS curves were obtained for Xp11.2 translocation and nonXp11.2 translocation groups using the Kaplan-Meier method and compared using a log-rank test. All statistical analyses were performed using SPSS, version 17 . In all analyses, calculated $P$ values of $<0.05$ were considered to indicate significance.

\section{Results}

Patients' outcome and pathologic results are shown in Table 1 . The Xp11.2 translocation RCCs were significantly associated with higher tumor grade and pathologic stage 
Table 1 Patient and tumor characteristics

\begin{tabular}{|c|c|c|c|}
\hline Variable & $\begin{array}{l}\text { non-Xp11.2 translocation } \\
\text { group }(n=82)\end{array}$ & $\begin{array}{l}\text { Xp11.2 translocation } \\
\text { group }(n=16)\end{array}$ & $P$ value \\
\hline Age(y) & & & 0.296 \\
\hline Media(Range) & $40(18-45)$ & $27(21-40)$ & \\
\hline Gender(n) & & & 0.086 \\
\hline Male & $56(68.3 \%)$ & 7 (43.8 \%) & \\
\hline Female & 25 (31.7 \%) & 9 (56.3 \%) & \\
\hline Size (cm) & & & 0.588 \\
\hline Media(Range) & $4.6(1.8-17.0)$ & $4.5(3.0-11.5)$ & \\
\hline Laterality(n) & & & 1.000 \\
\hline Left & 39 (47.6 \%) & 7 (43.8 \%) & \\
\hline Right & $43(52.4 \%)$ & $9(56.3 \%)$ & \\
\hline \multicolumn{4}{|l|}{ Symptoms(n) } \\
\hline Asymptomatic & 57 (69.5 \%) & $11(68.8 \%)$ & \\
\hline Symptomatic & $25(30.5 \%)$ & $5(31.3 \%)$ & 1.000 \\
\hline Nephrectomy (n) & & & 0.156 \\
\hline Radical & 49 (59.8 \%) & $13(81.3 \%)$ & \\
\hline Partial & 33 (40.2 \%) & $3(18.8 \%)$ & \\
\hline Overall stage(n) & & & 0.026 \\
\hline । & 57 (69.5 \%) & $10(62.5 \%)$ & \\
\hline$\|$ & $22(26.8 \%)$ & 2 (12.5 \%) & \\
\hline III & $2(2.4 \%)$ & $3(18.8 \%)$ & \\
\hline IV & 1 (1.2\%) & 1 (6.3 \%) & \\
\hline \multicolumn{4}{|l|}{ TNM(2010AJCC) } \\
\hline$T(n)$ & & & 0.026 \\
\hline $\mathrm{T} 1$ & $57(69.5 \%)$ & $10(62.5 \%)$ & \\
\hline $\mathrm{T} 2$ & $22(26.8 \%)$ & 2 (12.5 \%) & \\
\hline T3 & $2(2.4 \%)$ & $3(18.8 \%)$ & \\
\hline T4 & $1(1.2 \%)$ & $1(6.3 \%)$ & \\
\hline$N(n)$ & & & 0.013 \\
\hline $\mathrm{N}_{0}$ & 81 (98.8 \%) & $13(81.3 \%)$ & \\
\hline $\mathrm{N}_{1}$ & $1(1.2 \%)$ & $3(18.8 \%)$ & \\
\hline \multicolumn{4}{|l|}{$M(n)$} \\
\hline$M_{0}$ & $82(100 \%)$ & $16(100 \%)$ & \\
\hline$M_{1}$ & $0(0)$ & $0(0)$ & \\
\hline Tumor grade (n) & & & 0.011 \\
\hline Low & $25(30.5 \%)$ & $0(0 \%)$ & \\
\hline Medium & 38 (46.3 \%) & 9 (56.3 \%) & \\
\hline High & $19(23.2 \%)$ & 7 (43.8 \%) & \\
\hline Follow-up (mo) & & & 0.464 \\
\hline Media(Range) & $33.5(7-71)$ & $29(3-70)$ & \\
\hline
\end{tabular}

$(P<0.05$, Fisher's exact test $)$. No statistically significant difference was observed in age, gender, tumor size, laterality, symptoms at diagnosis, or surgical procedure.
The number of cancer-related deaths was 4 (4.9\%) and $3(18.7 \%)$ in the non-Xp11.2 translocation and Xp11.2 translocation groups, respectively. Analyses of CSS curves indicated that Xp11.2 translocation RCCs were significantly more frequently associated with a poorer outcome than non-Xp11.2 translocation RCCs $(P=0.042$, Fig. 1a).

A total of $12(14.6 \%)$ and 3 patients (18.7\%) in nonXp11.2 translocation and Xp11.2 translocation groups developed recurrence, respectively. The Kaplan-Meier RFS curves revealed no difference between these two groups $(P=0.505$, Fig. $1 b)$.

\section{Discussion}

Xp11.2 translocation RCC has been recognized as a distinct entity in the World Health Organization renal tumor classification scheme for 11 years. Its diagnosis is usually based on microscopic appearance and TFE3 immunostaining. Further diagnostic testing is difficult because fresh tissue collection for cytogenetics and molecular analysis is not routinely performed in adult RCCs. Polymerase chain reaction can also be used to confirm a specific gene translocation on formalin-fixed, paraffin-embedded tissue, but it is infrequently used as a clinical diagnostic tool and is more often used in the research setting. At present, the TFE3 break-apart FISH assay has been used to further confirm diagnosis of Xp11.2 translocation RCC [13-16].

The incidence of Xp11.2 translocation RCC is low. Previous studies have revealed an incidence of 0.9 (6/ 632) [8] to $5 \%(6 / 121)$ [17] in all adult RCCs and $15 \%$ $(4 / 26)$ in young adult RCCs [9]. According to age at the time of surgery, the incidence values of TFE3 positivity in the age ranges of $0-10,11-20,21-30$, and $31-40$ years were $67(2 / 3), 75(3 / 4), 29(2 / 7)$, and $14 \%(6 / 44)$, respectively $(P<0.001)$ [18]. Because RCC is more commonly encountered in the adult population, the amount of Xp11.2 translocation RCCs in adults may exceed that in the pediatric group. Our study revealed an incidence of $1.8 \%$ (16/879) in all adult RCCs and $15.5 \%(16 / 103)$ in young adult RCCs, which was consistent with previous reports.

Currently little is known concerning the biological behavior of Xp11.2 translocation RCCs because few clinical studies have been performed with a large sample size.

Based on the available data, the pediatric Xp11.2 translocation RCC is relatively inert, and its prognosis is better than that of adult Xp11.2 translocation RCC $[19,20]$. Song et al. [21] reported that pediatric Xp11.2 translocation RCC easily invaded regional lymph nodes and was highly malignant. However, patients with $\mathrm{N}+\mathrm{M} 0$ maintained a favorable prognosis following surgery alone.

Xp11.2 translocation RCCs that occur in adults may be more aggressive than those in children. Argani et al. [22] investigated 28 adult patients with Xp11.2 translocation 

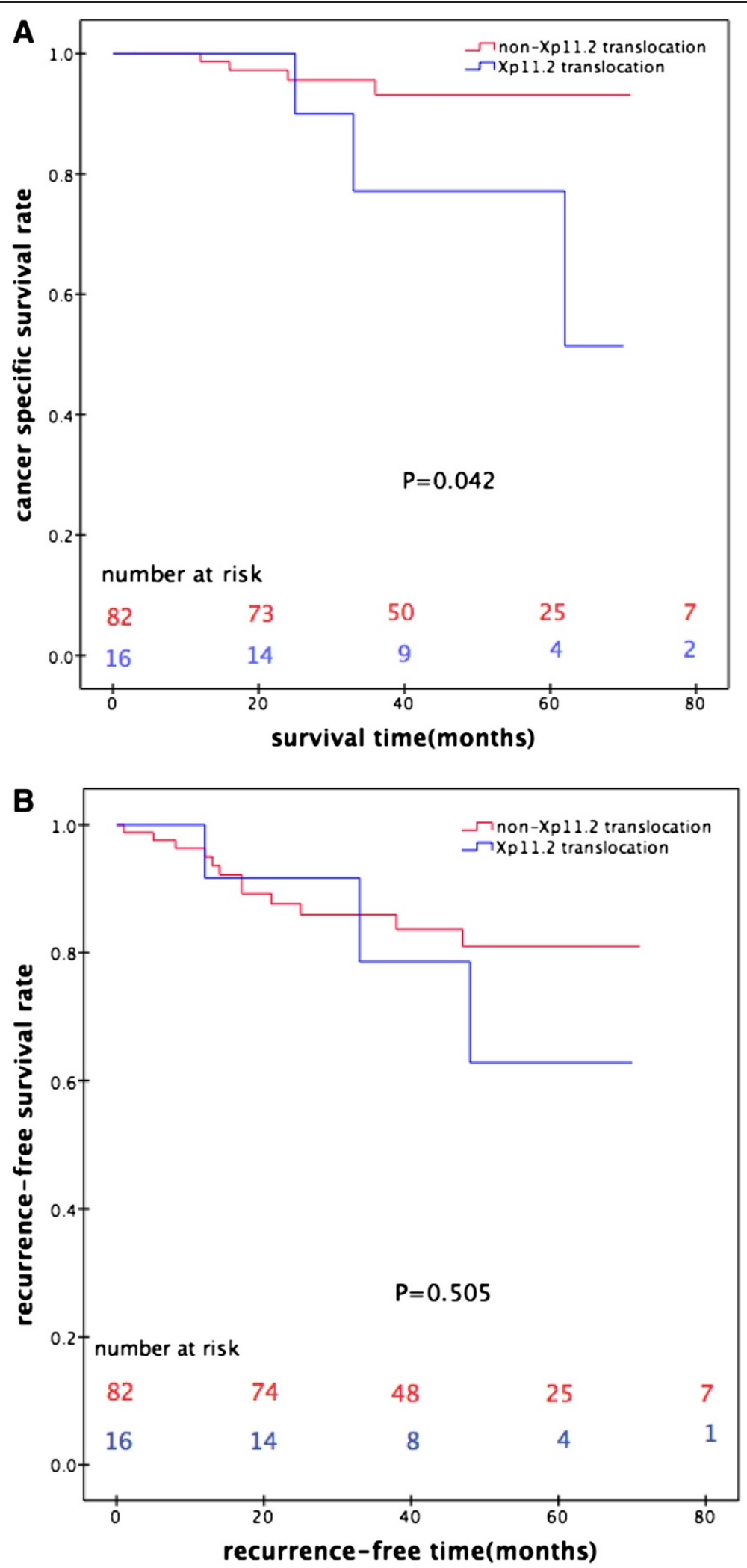

Fig. 1 Cancer-specific survival (a) and recurrence-specific survival (b) analyses were computed comparing non-Xp11.2 translocation renal cell carcinomas (RCCs) with Xp11.2 translocation RCCs in young adults. Red line: non-Xp11.2 translocation RCC; blue line: Xp11.2 translocation RCC 
RCC, including 16 patients with stage III-IV cancers. Lymph node metastasis occurred in 11 of 13 patients who could be evaluated. Meyer [23] examined 5 adult patients with Xp11.2 translocation RCC, all of whom were in the late stage of their disease with distant metastasis, rapid disease course, and poor outcomes with an average survival of 18 months. Of the 7 adult patients with Xp11.2 translocation RCC that Komai et al. [9] investigated, 5 were classified as stages III-IV and 2 died within 1 year. In a study by Zou et al. [24], the authors reported that 5 out of 9 Xp11.2 RCC patients presented with TNM stages $3-4$, and 6 died 10 months to 7 years after their operation. According to the review by Armah and Parwani [20], clinical and pathological heterogeneity may exist between pediatric Xp11.2 translocation RCC and adult Xp11.2 translocation RCC. Xp11.2 translocation RCCs had a high degree of invasiveness, rapid disease course, and poor prognosis in adolescents and adults over the age of 16 years, compared to that in children.

Xp11.2 translocation RCCs were extremely uncommon after 45 years of age, but this is likely an underestimation. Four patients reported by Arnoux [25] were older than 45 years, including three women (53, 71, and 75 years old) and one man (86 years old). One patient was metastatic at diagnosis. Radical nephrectomy was first performed in all cases. TNM staging was T3aN2R0, T3bNOR0, T2N2R0, and T3aN2R2, with a Furhman grade of 4 . Two patients progressed with metastasis 5 and 7 months after surgery, and two with lymphatic invasion 2 and 9 months after nephrectomy. One patient died during follow-up. Ellis et al. [26] confirmed that older age or advanced stage at presentation predicted death through multivariate analysis.

In this study, among 16 young adults with Xp11.2 translocation RCCs, 4 ( $25 \%$ ) were classified stage III-IV and 7 (43.8 \%) were Furman's grade 3-4. The KaplanMeier CSS curve revealed a significant difference between non-Xp11.2 translocation and Xp11.2 translocation groups. The results of the present study indicated that Xp11.2 translocation RCCs are associated with higher tumor grade and pathologic stage and poorer CCS in young adults.

Based on morphological appearance, RCC is subdivided into clear cell (70-80\%), papillary (10-15\%), chromophobe (3-5\%), collecting duct (1\%), and unclassified (1\%) subtypes [27]. Several studies have shown age to influence the distribution of histological subtypes $[12,28]$. A more consistent finding across several studies is that the proportion of tumors with chromophobe histology decreases with increasing age [12, 29, 30]. The clinical behavior of chromophobe RCCs is less aggressive than that of clear cell RCCs, independent of Fuhrman grade or tumor size [31]. The change of histological subtypes may be associated with better prognosis of nonXp11.2 translocation RCCs.
Similar to conventional RCCs, radical nephrectomy is recommended for Xp11.2 translocation RCCs. Nephronsparing surgery is an alternative with favorable outcomes in symptomless small RCCs [32]. For the treatment of adult metastatic Xp11.2 translocation RCCs, VEGF-targeted agents appear to demonstrate some efficacy [33].

Our study had several limitations. The sample size was small due to low incidence of this rare disease and the follow-up time was relatively short. The calculation was weak to answer the hypothesis. Thus, we should interpret the CSS curve with some caution before further follow-up is performed.

\section{Conclusions}

Our study showed that Xp11.2 translocation RCCs were seemingly associated with higher tumor grade and pathologic stage in young adults. Moreover, it seemed that Xp11.2 translocation RCCs had similar RFS rates but poorer CSS rates than non-Xp11.2 translocation RCCs in young adults. Our findings suggest that Xp11.2 translocation RCCs should be treated more actively and monitored by follow up.

\section{Abbreviations}

RCC: Renal cell carcinoma; TFE3: Transcription factor E3; TFEB: Transcription factor EB; FISH: Fluorescence in situ hybridization; CSS: Cancer specific survival; RFS: Recurrence-free survival.

\section{Competing interests}

The authors declare that they have no competing interests.

\section{Authors' contributions}

$L X$ and RY participated in the sequence alignment and drafted the manuscript. XC carried out the immunoassays. KF and GZ participated in the sequence alignment. $\mathrm{XQ}$ and $\mathrm{JH}$ participated in the design of the study and performed the statistical analysis. WG and HG conceived the study, participated in its design and coordination, and helped draft the manuscript. All authors read and approved the final manuscript.

\section{Acknowledgements}

We received financial support from National Natural Science Foundation of China (ID: 21377052), Natural Science Foundation of Jiangsu Province (ID: BK20131281), "Summit of the Six Top Talents" Program of Jiangsu Province (ID:WSN-005) and Nanjing health distinguished youth fund (ID:JQX12004).

Received: 15 December 2014 Accepted: 12 June 2015 Published online: 01 July 2015

\section{References}

1. Siegel R, Naishadham D, Jemal A. Cancer statistics, 2013. CA Cancer J Clin. 2013;63(1):11-30. doi:10.3322/caac.21166.

2. Rini BI, Campbell SC, Escudier B. Renal cell carcinoma. Lancet 2009;373(9669):1119-32. doi:10.1016/S0140-6736(09)60229-4

3. Argani P, Ladanyi M. Renal carcinomas associated with Xp11.2 translocations / TFE3 gene fusions. In: Eble JNSG, Epstein JI, Sesterhenn IA, editors.

Pathology and genetics of tumors of the urinary system and male genital organs. Lyon: IARC Press; 2004. p. 37.

4. Kuroda N, Mikami S, Pan CC, Cohen RJ, Hes O, Michal M, et al. Review of renal carcinoma associated with Xp11.2 translocations/TFE3 gene fusions with focus on pathobiological aspect. Histol Histopathol. 2012;27(2):133-40.

5. Argani P, Antonescu CR, Couturier J, Fournet JC, Sciot R, Debiec-Rychter M, et al. PRCC-TFE3 renal carcinomas: morphologic, immunohistochemical, ultrastructural, and molecular analysis of an entity associated with the t(X;1)(p11.2;q21). Am J Surg Pathol. 2002;26(12):1553-66. 
6. Argani P, Antonescu CR, Illei PB, Lui MY, Timmons CF, Newbury R, et al. Primary renal neoplasms with the ASPL-TFE3 gene fusion of alveolar soft part sarcoma: a distinctive tumor entity previously included among renal cell carcinomas of children and adolescents. Am J Pathol. 2001;159(1):179-92. doi:10.1016/S0002-9440(10)61684-7.

7. Argani P, Ladanyi M. Translocation carcinomas of the kidney. Clin Lab Med. 2005;25(2):363-78. doi:10.1016/j.cll.2005.01.008.

8. Sukov WR, Hodge JC, Lohse CM, Leibovich BC, Thompson RH, Pearce KE, et al. TFE3 rearrangements in adult renal cell carcinoma: clinical and pathologic features with outcome in a large series of consecutively treated patients. Am J Surg Pathol. 2012;36(5):663-70. doi:10.1097/ PAS.0b013e31824dd972.

9. Komai Y, Fujiwara M, Fujii Y, Mukai H, Yonese J, Kawakami S, et al. Adult Xp11 translocation renal cell carcinoma diagnosed by cytogenetics and immunohistochemistry. Clin Cancer Res. 2009;15(4):1170-6. doi:10.1158/ 1078-0432.CCR-08-1183.

10. Ramphal R, Pappo A, Zielenska M, Grant R, Ngan BY. Pediatric renal cell carcinoma: clinical, pathologic, and molecular abnormalities associated with the members of the mit transcription factor family. Am J Clin Pathol. 2006;126(3):349-64. doi:10.1309/98YE9E442AR7LX2X.

11. Qiu R, Bing G, Zhou XJ. Xp11.2 Translocation renal cell carcinomas have a poorer prognosis than non-Xp11.2 translocation carcinomas in children and young adults: a meta-analysis. Int J Surg Pathol. 2010;18(6):458-64. doi:10.1177/1066896910375565

12. Komai $Y$, Fujii $Y$, limura $Y$, Tatokoro $M$, Saito $K$, Otsuka $Y$, et al. Young age as favorable prognostic factor for cancer-specific survival in localized renal cell carcinoma. Urology. 2011;77(4):842-7. doi:10.1016/j.urology.2010.09.062.

13. Kim SH, Choi Y, Jeong HY, Lee K, Chae JY, Moon KC. Usefulness of a break-apart FISH assay in the diagnosis of Xp11.2 translocation renal cell carcinoma. Virchows Archiv. 2011:459(3):299-306. doi:10.1007/s00428-011-1127-5.

14. Mosquera JM, Dal Cin P, Mertz KD, Perner S, Davis IJ, Fisher DE, et al. Validation of a TFE3 break-apart FISH assay for Xp11.2 translocation renal cell carcinomas. Diagn Mol Pathol. 2011;20(3):129-37. doi:10.1097/PDM.0b013e31820e9c67.

15. Rao Q, Williamson SR, Zhang S, Eble JN, Grignon DJ, Wang M, et al. TFE3 break-apart FISH has a higher sensitivity for Xp11.2 translocation-associated renal cell carcinoma compared with TFE3 or cathepsin K immunohistochemical staining alone: expanding the morphologic spectrum. Am J Surg Pathol. 2013;37(6):804-15. doi:10.1097/PAS.0b013e31827e17cb.

16. Green WM, Yonescu R, Morsberger L, Morris K, Netto GJ, Epstein Jl, et al. Utilization of a TFE3 break-apart FISH assay in a renal tumor consultation service. Am J Surg Pathol. 2013;37(8):1150-63. doi:10.1097/PAS.0b013e31828a69ae.

17. Zhong M, De Angelo P, Osborne L, Paniz-Mondolfi AE, Geller M, Yang Y, et al. Translocation renal cell carcinomas in adults: a single-institution experience. Am J Surg Pathol. 2012;36(5):654-62. doi:10.1097/PAS.0b013e31824f24a6.

18. Klatte T, Streubel B, Wrba F, Remzi M, Krammer B, de Martino M, et al. Renal cell carcinoma associated with transcription factor E3 expression and Xp11.2 translocation: incidence, characteristics, and prognosis. Am J Clin Pathol. 2012;137(5):761-8. doi:10.1309/AJCPQ6LLFMC4OXGC.

19. Geller Jl, Argani P, Adeniran A, Hampton E, De Marzo A, Hicks J, et al. Translocation renal cell carcinoma: lack of negative impact due to lymph node spread. Cancer. 2008;112(7):1607-16. doi:10.1002/cncr.23331.

20. Armah HB, Parwani AV. Xp11.2 translocation renal cell carcinoma. Arch Pathol Lab Med. 2010;134(1):124-9.

21. Song HC, Sun N, Zhang WP, He L, Fu L, Huang C. Biological characteristics of pediatric renal cell carcinoma associated with Xp11.2 translocations/TFE3 gene fusions. J Pediatr Surg. 2014;49(4):539-42. doi:10.1016/j.jpedsurg.2013.10.005.

22. Argani P, Olgac S, Tickoo S, Goldfischer M, Moch H, Chan DY, et al. Adult Xp11 translocation renal cell carcinoma (RCC): Expanded clinical, pathologic, and genetic spectrum. Lab Invest. 2007;87:135a-a.

23. Meyer PN, Clark Jl, Flanigan RC, Picken MM. Xp11.2 translocation renal cell carcinoma with very aggressive course in five adults. Am J Clin Pathol. 2007;128(1):70-9. doi:10.1309/Lr5g1vmxpy3g0cuk.

24. Zou H, Kang X, Pang L, Hu W, Zhao J, Qi Y, et al. Xp11 translocation renal cell carcinoma in adults: a clinicopathological and comparative genomic hybridization study. Int J Clin Exp Pathol. 2014;7(1):236-45.

25. Arnoux V, Long JA, Fiard G, Pasquier D, Bensaadi L, Terrier N, et al. Xp11.2 translocation renal carcinoma in adults over 50 years of age: about four cases. Prog Urol. 2012;22(15):932-7. doi:10.1016/j.purol.2012.06.009.

26. Ellis $\mathrm{CL}$, Eble $\mathrm{JN}$, Subhawong $\mathrm{AP}$, Martignoni $\mathrm{G}$, Zhong $\mathrm{M}$, Ladanyi $\mathrm{M}$, et al. Clinical heterogeneity of Xp11 translocation renal cell carcinoma: impact of fusion subtype, age, and stage. Mod Pathol. 2014;27(6):875-86. doi:10.1038/modpathol.2013.208.

27. Störkel S, Eble JN, Adlakha K, Amin M, Blute ML, Bostwick DG, et al. Classification of renal cell carcinoma: Workgroup No. 1. Union Internationale Contre le Cancer (UICC) and the American Joint Committee on Cancer (AJCC). Cancer. 1997;80(5):987-9.

28. Verhoest G, Veillard D, Guille F, De La Taille A, Salomon L, Abbou CC, et al. Relationship between age at diagnosis and clinicopathologic features of renal cell carcinoma. Eur Urol. 2007;51(5):1298-304. doi:10.1016/ j.eururo.2006.11.056. discussion 304-5.

29. Jeong IG, Yoo CH, Song K, Park J, Cho YM, Song C, et al. Age at diagnosis is an independent predictor of small renal cell carcinoma recurrence-free survival. J Urol. 2009;182(2):445-50. doi:10.1016/j.juro.2009.04.013.

30. Suh JH, Oak T, Ro JY, Truong LD, Ayala AG, Shen SS. Clinicopathologic features of renal cell carcinoma in young adults: a comparison study with renal cell carcinoma in older patients. Int J Clin Exp Pathol. 2009;2(5):489-93.

31. Steffens $S$, Roos FC, Janssen M, Becker F, Steinestel J, Abbas M, et al. Clinical behavior of chromophobe renal cell carcinoma is less aggressive than that of clear cell renal cell carcinoma, independent of Fuhrman grade or tumor size. Virchows Arch. 2014;465(4):439-44. doi:10.1007/s00428-014-1648-9.

32. Xu L, Yang R, Wang W, Zhang Y, Gan W. Laparoscopic radiofrequency ablation-assisted enucleation of Xp11.2 translocation renal cell carcinoma: A case report. Oncol Letters. 2014;8(3):1237-9. doi:10.3892/ol.2014.2267.

33. Choueiri TK, Lim ZD, Hirsch MS, Tamboli P, Jonasch E, McDermott DF, et al. Vascular endothelial growth factor-targeted therapy for the treatment of adult metastatic Xp11.2 translocation renal cell carcinoma. Cancer. 2010;116(22):5219-25. doi:10.1002/cncr.25512.

\section{Submit your next manuscript to BioMed Central and take full advantage of:}

- Convenient online submission

- Thorough peer review

- No space constraints or color figure charges

- Immediate publication on acceptance

- Inclusion in PubMed, CAS, Scopus and Google Scholar

- Research which is freely available for redistribution

Submit your manuscript at www.biomedcentral.com/submit 